\title{
The representation of ethnic minorities at genetic clinics in Birmingham
}

\author{
Alexandra Roberts, Rose Cullen, Sarah Bundey
}

\begin{abstract}
A study of the ethnic distribution of families attending genetic clinics in Birmingham has shown a deficit of AfroCaribbean and Pakistani families. The former may be because of a deficiency of autosomal recessive diseases other than sickle cell disease, but the numbers are too small to be certain of this. The deficit of Pakistani families is probably for a variety of causes, such as a poorer attendance rate at clinics unless there is some encouragement, and a lack of awareness of, or interest in, genetic issues.

(f Med Genet 1996;33:56-58)
\end{abstract}

Key words: ethnic minorities; genetic clinics.

There was an impression among clinical geneticists in Birmingham that the numbers of clinic attenders from ethnic minority groups were not quite as might be expected. Therefore, a third year medical student project was designed to consider the ethnic distribution of families attending genetic clinics, and to consider the reasons for any discrepancies.

\section{Methods}

Computerised data on genetic clinic attendances were available from 1984 to 1994 . It was decided to restrict the study to the defined geographical area of the city of Birmingham. We also had to limit the study to the patients of one particular consultant (SB) as the other consultants did not record the ethnic group of their patients. We decided to count each family once only, to avoid any distortion that might be caused by some families with single gene disorders having many affected relatives.

We first compared the ethnic make up of clinic patients with that of residents in the city of Birmingham, as given by the 1991 census, ${ }^{1}$ and classified by age group. We only considered the four main ethnic groups: "White", AfroCaribbean, Indian, and Pakistani, preferring the term "European" to "White". We had insufficient patients in the "Black other", Bangladeshi, Chinese, or other ethnic groups to make comparisons meaningful. We classified Asians from East Africa as either Indian or Pakistani, according to the part of the Indian sub-continent from which they originated.

Secondly, we compared the ethnic make up of clinic patients with what might be expected from the frequency of genetic diseases in each ethnic group. The control data were taken from a prospective study of Birmingham children aged 0 to 5 years (table 1 ).

A separate study was performed by RC to determine whether, having been referred, there was any difference in the uptake (or non-attendance rate) between the four ethnic groups All referrals in the East Birmingham Health District in one year (1993-1994) were studied.

Lastly, AR interviewed members of three Pakistani families to ascertain their and their relatives' views on genetics and genetic counselling.

Significance tests for the differences between two proportions were carried out using the binomial distribution.

\section{Results}

The study included 567 families with addresses within the city of Birmingham who attended genetic clinics between the beginning of 1984 and the beginning of 1994 , approximately 10 years. There was an inconsistent pattern for registering families on the computer: sometimes the index patient was registered, and at other times a healthy relative who wanted advice was registered.

Looking at the age distribution in the different ethnic groups for the city of Birmingham, there was a tendency for the ethnic minority groups to have a lowered age distribution. However, there were no obvious differences in age distributions reflected in clinic attenders. Sixtynine percent of the registrants to the genetic clinics were aged between 15 and 44 years and the proportions of each ethnic group belonging to this age band in the population were very similar, namely 0.42 for European, 0.46 for Afro-Caribbeans, 0.52 for Indians, and 0.44 for Pakistanis.

The numbers and proportions of clinic families in the four main ethnic groups are given in table 2 and compared to the proportions observed among Birmingham residents from the 1991 census. ${ }^{1}$ It was found that 215 families $(38 \%)$ attended because of a single gene dis-

Table 1 Incidence of single gene diseases in Birmingham children aged 0-5 years*

\begin{tabular}{lccc}
\hline & Numbers & $\begin{array}{c}\text { Incidence } \\
\text { per } 1000\end{array}$ & 2 SE range \\
\hline European & $11 / 2241$ & $4 \cdot 91$ & $4 \cdot 62-5 \cdot 20$ \\
Afro-Caribbean & $2 / 453$ & $4 \cdot 41$ & $3 \cdot 80-5 \cdot 02$ \\
Indian & $2 / 619$ & $3 \cdot 23$ & $2 \cdot 79-3 \cdot 67$ \\
Pakistani & $36 / 952 \dagger$ & $37 \cdot 8 \dagger$ & $34 \cdot 0-41 \cdot 6$ \\
\hline
\end{tabular}

* The data are taken from Bundey, ${ }^{2}$ table $8 \cdot 5$, and Bundey and Alam, ${ }^{3}$ appendix 16 .

† The numbers and incidence fall to $16 / 952$ and 16.8 if children with probable (but not certain) autosomal recessive diseases are excluded. 
Table 2 Genetic clinic families compared to ethnic group distribution of the 1991 census $^{1}$

\begin{tabular}{|c|c|c|c|c|c|c|}
\hline \multirow[t]{2}{*}{ Ethnic group } & \multicolumn{2}{|c|}{ Clinic families } & \multicolumn{2}{|c|}{$\begin{array}{l}\text { Birmingham residents } \\
\text { (all ages) }\end{array}$} & \multicolumn{2}{|c|}{$\begin{array}{l}\text { Expected from data in } \\
\text { table } 1 \text { (see text) }\end{array}$} \\
\hline & No & $\%$ & No & $\%$ & Ratios & $\%$ \\
\hline $\begin{array}{l}\text { European } \\
\text { Afro-Caribbean* } \\
\text { Indian } \\
\text { Pakistani }\end{array}$ & $\begin{array}{r}444 \\
15 \\
34 \\
74\end{array}$ & $\begin{array}{r}78 \cdot 3 \\
2 \cdot 6 \\
6 \cdot 0 \\
13 \cdot 1\end{array}$ & $\begin{array}{r}743415 \\
46783 \\
50881 \\
65914\end{array}$ & $\begin{array}{r}82 \cdot 0 \\
5 \cdot 2 \\
5 \cdot 6 \\
7 \cdot 3\end{array}$ & $\begin{array}{r}82 \cdot 0 \\
5 \cdot 2 \\
5 \cdot 6 \\
21 \cdot 9\end{array}$ & $\begin{array}{r}71 \cdot 5 \\
4 \cdot 5 \\
4 \cdot 9 \\
19 \cdot 1\end{array}$ \\
\hline
\end{tabular}

* Black Caribbean plus Black African.

Table 3 Attendance rates at genetic clinics (1993-1994), East Birmingham Health District*

\begin{tabular}{lcll}
\hline Ethic group & No of referrals & $\begin{array}{l}\text { Attendance at first } \\
\text { appointment }\end{array}$ & $\begin{array}{l}\text { Attendance at first or } \\
\text { second appointments }\end{array}$ \\
\hline European & 69 & $57(83 \%)$ & $66(96 \%)$ \\
Afro-Caribbean & 1 & 1 & 1 \\
Indian & 0 & N/A & N/A \\
Pakistani & 34 & $21(62 \%)$ & $26(76 \%)$ \\
Totals & 104 & $79(76 \%)$ & $93(89 \%)$ \\
\hline
\end{tabular}

* The proportion of Pakistanis in this health district is $12 \%$, not $7 \%$ as in Birmingham as a whole.

order which presented in childhood, 261 families $(46 \%)$ because of a single gene disorder presenting in adult life, and 91 (16\%) for other reasons. Keeping these figures in mind we then considered what might be the expected numbers of families with genetic enquiries based on the incidence of childhood genetic diseases in the different ethnic groups that have been presented in table 1 . As the incidences in the first three ethnic groups (European, AfroCaribbeans, and Indians) are similar, these groups would be expected to attend genetic clinics in the same proportion as the general population. However, as childhood genetic diseases are eight times more common in Pakistanis, there should be a relative increase in their attendance, but only in reference to the $38 \%$ of genetic clinic referrals for childhood onset genetic diseases. Therefore the proportion of Pakistani families expected to be seen in a genetic clinic should be increased by three times $(35 \% \times 8)$ compared to their proportion in the population. As the percentage of Pakistani families found in the general population is $7 \cdot 3$, the percentage expected at clinics on account of their genetic diseases should be $7 \cdot 3 \times 3$, or $21 \cdot 9$. This figure has been turned into a percentage of the whole group of clinic attendees in the last column of table 2. The expected percentage of Pakistani attenders now becomes $19 \cdot 1$ (while the percentages in the other groups fall). This percentage of $19 \cdot 1$ is greater than the $13 \cdot 1$ observed among clinic attenders $(p=0.06)$.

Study of the attendances at first clinic appointments showed a poorer first attendance rate for Pakistani families. Their attendance rate improved when a second clinic appointment was offered but their overall attendance rate was poor (table 3). However, it was noted that for another, specialist, clinic, attendance was nearly $100 \%$ if contact was made beforehand by a Pakistani doctor. There is no indication in table 3 of a deficit of a doctor initiated referrals of Pakistani families to genetic clinics.
AR interviewed Pakistanis who had attended for genetic counselling and learnt that they found it to be important and useful. However, she also heard about the views of their relatives, particularly those of members of the previous generation, in that they did not understand genetic concepts and did not consider that there should be interference with the natural course of events. There had also been misunderstandings about what would happen at a genetic clinic, and anxieties about whether an Urdu, Punjabi, or Bangladeshi speaking counsellor would be present.

\section{Discussion}

A number of assumptions have had to be made in this study. We have assumed that the clientele of SB is representative of all ethnic groups and of all types of genetic diseases which occur within the city of Birmingham. In fact, SB probably sees more families with adult onset diseases than her colleagues. However, we could not include all Birmingham families seen in genetic clinics as ethnic group has not, up until now, been documented in them all. We have assumed that by counting only one member of each family, any bias owing to large pedigrees of Huntington's disease, myotonic dystrophy, or autosomal recessive diseases in inbred families has been avoided.

We first compared the distribution of ethnic group of our clinic families with the ethnic groups of Birmingham residents in the 1991 census. Because of the age distribution already described, we considered that there was no reason to make any adjustments for age. Table 2 shows a deficiency of Afro-Caribbeans attending genetic clinics. This may be because counselling for sickle cell disease is provided by the Birmingham Sickle Cell and Thalassaemia Centre, so that families with sickle cell disease are never seen in the genetic clinics. It is possible that there is a deficit of autosomal recessive diseases other than sickle cell disease in this ethnic group, but the numbers are far too small to reach significance; it is perhaps a point worth considering in a larger study.

Table 2 also shows that the number of $\mathrm{Pa}$ kistani families seen in genetic clinics was greater than expected from the population data. ${ }^{1}$ However, the numbers were lower than expected from the incidence of genetic disease in that ethnic group; $13 \%$ of the families were Pakistani, whereas about $22 \%$ might have been expected. There could be several reasons for this deficit.

Firstly, general practitioners might refer $\mathrm{Pa}-$ kistani families with genetic disorders less frequently than families from other ethnic groups. This could be because of lack of awareness of diseases that might be helped by members of a genetics department. However, if this were so, a different pattern of referral for patients in different ethnic groups would not be expected. Another possibility is that general practitioners might consider that Pakistani families would not wish to be referred for genetic counselling, because of their religious beliefs or cultural attitudes. However, reference to table 3 shows 
that $34 \%$ of the clinic referrals in East Birmingham Health District were for Pakistani families, making it unlikely that a marked shortfall of referrals exists. A study in Oxford ${ }^{4}$ showed that general practitioners with $\mathrm{Pa}-$ kistani families on their lists were aware of their genetic needs.

A second reason for failure to see Pakistani families in genetic clinics might be that such families are frightened by the idea of a genetic interview, particularly if their knowledge of English is poor. Mehta and Young ${ }^{5}$ noted that the presence of an interpreter and a knowledge that one would be present was helpful to Asian families. This view is supported by our observation of nearly $100 \%$ attendance if a $\mathrm{Pa}-$ kistani doctor telephoned before the clinic to encourage attendance, and to explain that she would be present to act as interpreter.

Thirdly, Pakistani families may be slow themselves to initiate referrals to a genetic clinic, because of a lack of understanding of biology and inheritance. Lawry ${ }^{4}$ observed that there was insufficient awareness of genetic diseases by the Pakistani community, and insufficient educational material or information leaflets available in doctors' surgeries or elsewhere. This was also the opinion of the staff of the Birmingham Sickle Cell and Thalassaemia Centre, who send leaflets in appropriate languages to all those found to be carriers of sickle cell disease or thalassaemia, and who provide a full time counsellor to explain the issues to carriers and to visit and advise families who already have an affected child. However, in spite of this availability of information, the staff of the Centre feel that further education of the community is required.

As a result of this study we have concluded that genetic clinics should be made more comfortable for Pakistani families, with an explanation beforehand of what to expect, an appropriate interpreter at the clinic, and the availability of support by a Pakistani nurse or fieldworker after the clinic. We also believe that education of the community about genetic issues is important, and that these should include a biological explanation of relationships, with emphasis on the random nature of genetic disease, to aim at avoiding stigmatisation of carriers. Darr ${ }^{6}$ showed clearly in a study from Bradford that families with a thalassaemic child were very receptive to genetic counselling, including involvement of the extended family, and they wish to hear about the options of carrier testing and prenatal diagnosis.

We have started to improve genetic services for Pakistani families by holding regular genetic clinics shared with a Pakistani Muslim doctor, and we have appointed a full time Muslim fieldworker to initiate an education programme and to help in genetic clinics. We have also prepared leaflets about genetic counselling, recessive diseases, and consanguinity which are available in doctors' surgeries, health centres, and welfare clinics.

Finally, we would like to encourage documentation of ethnic group on genetic clinic records. This is considered important by NHS administrators for the purpose of auditing their service, but surely it should be equally important for geneticists, as ethnic origin of a patient is one of the most important genetic characteristics.

We thank Mrs Sue Lawry for allowing us to read her dissertation, and we thank her and Mrs Lilieth Smith and Sister Eboh of the Birmingham Sickle Cell and Thalassaemia Centre for helpful discussions.

1 Office of Population and Census Surveys (OPCS). 1991 County report: West Midlands, part 1, table 51.

2 Bundey S. A prospective study on the health of Birmingham babies in different ethnic groups: interim findings. In: Bittles AH, Roberts DF, eds. Minority populations: genetics, demography and health. Basingstoke: MacMillan, 1992: 143-55.

3 Bundey S, Alam H. A five-year prospective study of the health of children in different ethnic groups. Eur $\mathcal{F}$ Hum Genet 1993;1:206-19.

4 Lawry S. Thalassaemia - access to appropriate screening and counselling care for Muslims of Pakistani origin in Oxford. Dissertation submitted for BSc (Hons) in Anthropolog and Geography at Oxford Brookes University, Oxford, 1993.

5 Mehta L, Young ID. Attitudes of Asian families to genetic counselling. F Med Genet 1985;22:413.

6 Darr A. The social implications of thalassaemia among Muslims of Pakistani origin in England - family experience and service delivery. PhD thesis, University of London, 1991. 